\title{
Entre mostrar e vivenciar: cenas do teatro do real
}

\begin{abstract}
André Carreira ${ }^{1}$
Ana Maria de Bulhões-Carvalho²

\section{Resumo}

Este texto discute a ideia de um Teatro do Real considerando a tensão entre o real tratado como tema, e o real como experiência compartilhada entre atores e espectadores. $\mathrm{O}$ artigo ainda se pergunta quais são os objetivos da cena que visita o difuso território de um teatro do real, cuja condição básica da identificação é circunstancial e relativa. Finalmente, os autores delimitam como ponto de partida da cena do real o encontro entre espectadores e atores.
\end{abstract}

Palavras-chave: realidade; ficção; representação.

\section{Resumen}

Este texto discute la idea de un Teatro de lo Real considerando la tensión entre lo real tratado como tema, y lo real como experiencia compartida entre actores y espectadores. el artículo también se pregunta cuales Sn los objetivos de una escena que visita el territorio de un teatro de lo real, cuya condición básica de la identificación es circunstancial y relativa. Finalmente, los autores delimitan como punto de partida de la escena de lo real el encuentro entre espectadores y actores.

Palabras-Ilave: realidad; ficción; representación.

\section{Abstract}

This paper discusses the idea of a Theatre of the Real considering the tension between the real as a subject, and the real as an experience shared between actors and spectators. The article also asks what this theatre's objectives are. The authors define the starting point of the Real's scene as the encounter between spectators and actors.

Keywords: reality; fiction; representation.

É já uma evidência a adoção definitiva, pela cultura ocidental, daquilo que se convenciona chamar "teatro do real", ainda que não haja entendimento particular sobre o sentido exato do termo. É inegável, no entanto, certo consenso sobre sua abrangência, que inclui indiferentemente uma nomenclatura que trata de dar conta das

\footnotetext{
1 Doutorado em Teatro pela Universidad de Buenos Aires (1994) atualmente é professor da Universidade do Estado de Santa Catarina (UDESC). Dirige os grupos teatrais Experiência Subterrânea de Florianópolis e Teatro que Roda. É bolsista de Produtividade de Pesquisa do CNPq (1C).

2 Pós-doutora em Letras Puc-Rj (2008-2009), Doutora em Literatura comparada (UFRJ,1997) é professora adjunta do PPGAC e de Teoria do Teatro, CLA (UNIRIO); coordenadora de Literatura na formação do leitor, na Licenciatura em Pedagogia a distância (CEDERJ-UNIRIO). É bolsista de Produtividade de Pesquisa do CNPq (2).
} 
propostas desse teatro que busca o real como elemento, e pode ir do biodrama ao teatro autobiográfico, passando pelo teatro documentário, teatro reportagem, até pelo docudrama. Frente a esta variedade de formatos e nomes cabe perguntar quais são os objetivos da cena que visita o difuso território de um teatro do real? Podem-se questionar as experiências relacionadas com uma cena do real como uma nova vertente do nosso teatro? Caberia perguntar em que medida o trabalho com o real como produtor de efeitos de realidade se relaciona com as estratégias de mercado, ou se ele representa uma transformação efetiva das relações constituintes da cena?

Essas são questões que merecem ocupar a atenção dos que buscam realizar um teatro que se reivindica partícipe de uma cena do real.

De qualquer modo, todos eles referem a um teatro que enfatiza uma relação explícita, tanto textual quanto cênica, com o real factual, no sentido político, social, coletivo ou individual. A abrangência do termo engloba uma grande variedade de modos de criação de forma a evidenciar suas fontes documentais, que podem advir de transcrições, gravações, entrevistas, depoimentos, documentários, fotografias, entre outros, e podem incluir o deslocamento espacial para algum site specific (isso é, espaços que se tornam teatrais pelo uso, mas que tem outras funções na vida real), ou serem transmitidos ao vivo pela internet, em tempo real: o importante é que produzam um "efeito de real" (BARTHES, 2004), um efeito que confira alguma legitimidade e evidencie a relação do que traz a arte com o real verdadeiro, ou até mesmo, que seja realmente verdadeiro o que se tome como arte.

Tome-se como ponto de partida para a aproximação desse vasto campo o exemplo extremo que dá Carol Martin (2013), no capítulo de abertura do livro Theatre of the Real. Essa autora se refere ao espetáculo Is.Man, do holandês Adelheid Roosen, de 2007, apresentado no St. Anne's Warehouse, em DUMBO (N.Y.)³, e lembra que, logo no início da apresentação a que ela assistiu, a de estreia do espetáculo, o ator prin-

\footnotetext{
3 A sigla DUMBO significa "Down Under the Bridge Overpass Manhattan" e descreve o antigo bairro industrial ao longo da orla Brooklyn. O principal entre muitos atrativos de DUMBO é sua irrestrita vista para o horizonte de Manhattan. O novo armazém de St. Ann, em 29 Jay Street, está a poucos quarteirões da margem do rio e da ponte de Brooklyn Park e oferece uma perspectiva deslumbrante da ponte de Manhattan. Para além do parque, junto às águas, nas ruas de paralelepípedos há várias surpresas: um chocolatier, estúdios de arte e galerias, fabricantes de móveis e os vendedores de varejo, uma fábrica de sorvete, um carrossel vintage restaurado e a instalação monumental, de acrílico recuperado e aço manchado, intitulada Watertower, do artista Tom Fruin, que adiciona brilho e cor ao já deslumbrante horizonte do Brooklyn e até mesmo. O site consultado ainda aconselha: "Não coma antes de vir para o armazém de St. Ann. Há boa comida em DUMBO uma curta distância! Disponivel em: <http://www.stannswarehouse.org/about_dumbo.php>. Acesso em 20 de setembro de 2013.
} 
cipal, Youssef Sjoerd Idilbi, teve problemas com seu microfone, aparelho indispensável considerando a dimensão do espaço. O som foi e voltou várias vezes, mas o ator continuava sua atuação, obrigando o público a compensar a altura do som inclinando-se na direção da cena. Mas num momento de clímax, tendo faltado completamente o som, o ator abandonou a cena abruptamente e, em seguida, o público ouviu o forte bater de uma porta nos bastidores. Ali ela percebeu que se estabelecera a dúvida geral: do que se tratava? Essas interrupções estavam previstas no espetáculo, ou seriam "uma rude irrupção da vida real numa peça sobre eventos reais?" (MARTIN, 2013, p.3). A própria Martin, a despeito de sua experiência artística, honestamente manifesta sua dúvida como espectadora-partícipe do acontecimento. E por que surgiu a dúvida? Porque todos ali pagaram para assistir à estreia de um espetáculo, portanto, o que ocorresse na cena deveria, pelos termos de um pacto mudo convencionado, estar previsto, ensaiado, preparado para ser mostrado. Isso passaria a incluir as possíveis falhas, inimagináveis, porque a ficção, supostamente, não admitiria erros.

O exemplo é provocativamente uma extremada circunstância da confusão entre o real e o ficcional a que a nossa contemporaneidade já se acostumou. Se o real no teatro pode ser um elemento que irrompe, na tessitura da cena, como acontecimento, sem que nem atores, nem espectadores possam controlar suas operações, ele também pode se manifestar de outras maneiras, com diferentes objetivos. O pressuposto do que hoje se convenciona chamar "teatro do real" ou "cena do real" é que tudo o que ocorre na cena pode ser documentado e foi baseado em pesquisa de arquivos e registros, ainda que possa resultar em espetáculos que tomem diferentes formas, perspectivas, formas e métodos. Supõe que se possa considerar o real na cena como constatação de uma informação que se assegure verdadeira, matéria real concreta, verificável pelo depoimento das várias testemunhas que a presenciam. Essa matéria que se verifica na cena é real em si, constitui um campo de observação quase autônomo, independente.

No entanto, essa postura alerta e participativa do espectador tem como consequência, um pacto de ambiguidade que se estabelece com aquilo que é visto, testemunhado, já que aquela cena não pode ser transformada pela ação das testemunhas, ainda que elas estejam creditando a ela uma verdade. Pois ainda que credível e "real", a cena é teatral. Essa é sua condição, sempre contraditória e ambígua. Trata-se de uma cena testemunhada no teatro, e por mais realidade que dê a observar, essa realidade está, desde o início, comprometida pelas circunstâncias de sua irrupção: ela se 
dá num espaço de convenções pré-estabelecidas. O simples fato de estar ocorrendo ali, naquele lugar denominado "espaço teatral", compromete e determina a natureza daquele real. Ainda que provoque uma experiência verdadeira, essa experiência tem valor de signo, é convencionada, ainda que esse signo nasça do contato com o real. ${ }^{4}$

Em relação à ocorrência do real no teatro, pode-se considerar que ela opera uma espécie de desvio, um desvio para o real. Como? Ao longo de sua história no ocidente, o teatro foi um lugar da referência ao real transformado em ficção. As primeiras referências sendo o mito, uma forma simples de dar a entender o homem na sua relação com os outros homens e com o universo em que se insere, a natureza do teatro é de ser criação, recriação do mundo a partir de uma determinada ótica, valendo-se de homens que, em suas ações, simulam uma realidade que não está ali. O teatro sempre foi uma forma de chamar aos olhos de testemunhas o mundo que não está ali, para torná-lo compreensível ou para questioná-lo, para expor suas precariedades, suas estranhezas. Esse teatro não tinha pudor de ser uma interpretação, de apresentar uma visão, de oferecer um sucedâneo desse real numa representação, numa cópia.

Mas não é nesse sentido que hoje se adjetiva o teatro como "teatro do real", obviamente. O termo no sentido ampliado em que ele passou a frequentar os estudos teatrais constitui um novo modo de ser da cena.

Os espetáculos que utilizam o real como matéria, ou dialogam com o real como tema, pedem uma reflexão sobre como podemos construir percepções do real que se projetam para além do efeito imediato, sustentado principalmente pela informação de sua presença na cena. É central refletir se tais propostas constituem um material que efetivamente desestabiliza os modelos teatrais estabelecidos, como parece ser o objetivo principal dessas experiências cênicas.

Em primeiro lugar, seria oportuno questionar o que pode ser considerado o real na cena. Discutir as relações entre o real e o ficcional é adentrar num terreno escorregadio, pois, só podemos dizer que do real sabemos sobre a hipótese de sua manifestação. A condição básica da identificação do real é circunstancial e relativa. (É o real para mim, o real que eu vejo, ou que nós vemos). Portanto, esse reconhecimento ou sua constatação são parte de um complexo processo de aceitação e descobrimentos,

\footnotetext{
4 Portanto, essa moldura teatral, ainda que não impeça que se estabeleça também aí aquilo que o filósofo espanhol José Sanchez considera como conceito contemporâneo de realidade, indissociável da relação intersubjetiva: se a realidade são os outros, o real é a relação mesma, um real é imaterial, e somente representável como processo. A impossibilidade de dar forma visível ao real não anularia a possibilidade de conhecer a realidade e se intervir nela, em um momento dado e em um contexto concreto (SANCHEZ, 2007).
} 
frente aos quais os espectadores e os atores são participantes ativos em um jogo de acordos, encontros e desencontros. A percepção do real pode criar um tipo de compromisso com o que é referenciado na cena, e a partir do que é possível identificar os processos reais (e atuais) dos quais cada um participa, individualmente ou numa coletividade. Refletir sobre estas questões tem como objetivo estimular uma discussão, não apenas sobre espetáculos específicos, como também a cerca de modelos teatrais e referenciais teóricos que funcionam no nosso sistema teatral.

Maryvonne Saison (1998), em seu livro fundador dos estudos do teatro do real, Les théâtres du réel, diz que o real autêntico na performance teatral é contraditoriamente alcançado pela admissão de sua artificialidade, pois a representação "independentemente de qualquer gesto mimético, coloca a dimensão da referência, pois ela sempre convoca uma entrada de referência: a representação difere da coisa, porque existe apenas como representação quando é considerada como tal" (SAISON, 1998, p.87). O reconhecimento da representação por parte do espectador é o elemento chave que permite exatamente a identificação do real. A diferenciação com a "coisa", como aponta Saison, produz aquilo que particulariza o real da representação. Em se tratando do teatro, a impossibilidade da completa ilusão de realidade reafirma a teatralidade como instrumento da irrupção do real. Nesse caso, para que o real surja é preciso que o espectador perceba como o procedimento ficcional o conduz à experiência da realidade e, como isso, transforma o ato da recepção. Ainda que essa percepção não seja de todo consciente como processo, o espectador percebe o seu efeito.

Para contribuir com essa reflexão, podem-se identificar, na abrangente listagem de nomenclaturas que dão suporte ao "teatro do real", duas grandes correntes: 1) uma que, principalmente, toma o real como elemento temático, isso é, sua proposta inicia a inovação na própria dramaturgia textual, no arrolamento de materiais, de documentos e no seu agenciamento pela criação dramatúrgica; 2) e uma segunda, que privilegia o real como matéria da experiência na cena, o real como acontecimento, como irrupção no tecido ficcional.

Para efeito da abordagem deste artigo, direcionamos o olhar para as reverberações da cena que podem vincular-se com o real. Nesse sentido, a interpretação e seus procedimentos são um território a ser visitado, pois na experiência concreta do ator residem elementos centrais para a verificação do que pode ser real na cena. É por meio do ator que podemos encontrar dimensões do real diretamente relacionadas 
com aquilo que é central no evento teatral: o encontro com o público; a materialidade do fazer teatro como experiência compartilhada.

Ao refletir sobre a prática cênica que se alicerça nas relações com o real, a diretora e autora argentina Beatriz Catani diz que: "trata-se de querer que uma coisa seja o mais real possível e ao mesmo tempo profundamente sugestiva. Ou que a coisa abra áreas de sensações distintas da simples representação" (CATANI, 2008). Esta diretora experimenta, em seus espetáculos, os níveis de representação e apresentação a fim de fazer do teatral "uma realidade na qual, a partir da distorção e do barramento do 'real-aparente', se chegue a um registro sensível e próprio do 'real'”. (CATANI, 2008)

Muitos são os exemplos de formas de tratamento do teatro do real a que se poderia recorrer neste artigo, considerando, como matéria de reflexão, as formas expostas por um teatro mais próximo de nós, latino americano ou brasileiro. Uma dessas formas é, com certeza, o "biodrama", termo cunhado pela dramaturga e encenadora argentina Vivi Tellas, título de um projeto que durou de 2002 a 2009, no qual foram apresentados espetáculos teatrais que tinham como eixo a encenação de histórias sobre pessoas vivas, que deveriam participar diretamente das encenações, de algum modo. Sobre essa proposta, lembra o pesquisador Óscar Cornago que, a despeito da tensão entre realidade e ficção estar presente em diferentes peças e montagens teatrais, no Projeto Biodrama:

\footnotetext{
Este comportamento se faz explícito. A partir daí, o Biodrama propõe uma dupla questão: por um lado, o efeito do olhar teatral sobre a realidade; por outro, o comportamento do teatro diante da introdução de elementos reais. O projeto nos lança, portanto, uma interrogação de mão dupla, que parte do teatro para voltar ele, e que, no fundo, oculta esse profundo sentimento de crise da realidade e, por conseguinte, crise das formas dominantes da representação do real pela ficção. (CORNAGO, 2009, p. 15)
}

A tensão entre a ficção e a realidade se estrutura como consequência de uma visão que reconhece a teatralidade como produtora de "um campo de realidade, de um espaço que vai funcionar como espaço de atuação". (CORNAGO, 2009, p. 22)

José Antonio Sanchez (2007) em seu livro Prácticas de lo Real en la Escena Contemporánea diferencia a busca do real, ou da realidade, da irrupção do real. A irrupção do real deveria ser compreendida como efeito da operação da cena, isto é, como resultante da experiência do espetáculo, por isso, seria da ordem do acontecimento. Quando o real irrompe na cena observamos o deslocamento do eixo espetacular, isto é, do mostrar para o experimentar. Sanchez diz que:

A representação da realidade é, de fato, um problema muito distinto ao da irrupção do real. Em alguns casos ambas ações podem coincidir e a presença do real pode servir para garantir a efetividade de uma representação. No 
entanto, em muitos casos, a representação do real não é mais que uma desculpa, inclusive uma armadilha, quando do que se trata é precisamente de renunciar a uma construção dos fatos com sentido, isto é, de uma realidade compartilhada ou suscetível de ser compartilhada. (SANCHEZ, 2007, p.2)

As práticas do teatro do real devem ser relacionadas com o "ser", em oposição com o "mostrar". Isso supõe uma aproximação com acepção do termo "experiência" para Agamben, considerando que experiência seria um insight decorrente de um certo desencontro, de um descompasso, onde as palavras são insuficientes. A experiência ocorreria entre o "não-ainda" (da inter-dicção auspiciosa) e o "só-depois" (da significação) (AGAMBEN, 2005). Assim, podemos associar esta ideia com o "desejo de produzir experiências verdadeiras que favorecem a utilização de formas de atuação na primeira pessoa cuja verdade (da representação) remete [...] às confissões e testemunhos pensados como dispositivos de enunciação" (CORNAGO, 2009, p.100).

Por outro lado, pode-se ampliar o campo de observação sugerido pela profusão de espetáculos que fazem menção à presença do real como elemento central da cena considerando que é uma tendência mais ampla da cultura atual no ocidente. Isso não é, obviamente, exclusividade do teatro. No universo do cinema e da televisão há muitos exemplos de projetos que sustentam sua divulgação e comercialização no fato de que estão "baseados em fatos reais", ou de que o público verá cenas reais. Nos últimos anos a televisão tem sido pródiga em produtos articulados a partir da explicitação de supostos materiais reais. Temos no ar e no cabo, inúmeros programas no quais se espetaculariza o privado substituindo a realidade histórica (coletiva) pelo real (individual) (SANCHEZ, 2007). A internet está cheia de exemplos da atenção que conseguem os vídeos e as fotos de fatos reais. Ver o real é um desejo difundido e aceitado como demanda da cultura, e tem alcançado tal dimensão que se tornou difícil reconhecer a autenticidade daquilo que seria realidade.

Nossa desconfiança com relação às narrativas que parecem oferecem simulacros de real abre espaço para que busquemos algo mais sólido como referências que nos situem no mundo. $O$ teatro tem feito esforços nesse sentido, portanto, é preciso considerar as experiências do teatro do real em um contexto no qual se tornou usual, principalmente nos meios de comunicação de massa e nas práticas políticas, o procedimento da confusão entre a realidade e a ficção. Paradoxalmente, esse teatro experimenta exatamente com formas que fundem o ficcional com o real para produzir novas possibilidades de discussão da realidade.

Ao anunciar o real como elemento da ficção, o teatro está convocando o olhar do espectador a elaborar uma ampla série de hipóteses sobre a própria operação da 
ficção e da criação artística. Isso está relacionado com a constatação de que vivemos em um mundo onde o real se mescla com o ficcional nos mais diferentes ambientes. Não se trata de uma particularidade do teatro, mas, de um procedimento que tem penetrado sistematicamente o mundo das comunicações. Se esses dois campos, realidade e ficção, parecem bem diferenciados, desde a experiência radiofônica de $A$ Guerra dos Mundos protagonizada por Orson Welles, até o excesso dos reality shows, as fronteiras entre o ficcional e o real foram sendo borradas.

$\mathrm{Na}$ contra mão dessa tendência o teatro tem empreendido diferentes esforços no sentido de recuperar o real como elemento central de uma cena que trata de fissurar a predominância da ficção que invade o cotidiano. Isso não implica em negar a importância da dimensão narrativa e ficcional da experiência humana, mas, de colocar em crise o velamento dos elementos da realidade pelos procedimentos espetaculares da sociedade do hiperconsumo, tal como apontam as críticas de Guy Debord e a Internacional Situacionista. Portanto, pode-se pensar as propostas do teatro do real como práticas que reforçam os procedimentos da teatralidade realizando um retorno ao real, com vistas a criar novas tensões entre a arte e a vida. Nesse sentido, o real não seria um efeito, mas sim um contexto que coloca em tensão o eixo central do teatro, como foi dito anteriormente: o vínculo entre o público e os atores. O real como moeda corrente de um teatro que pretende construir um espaço de pertencimento, como alternativa ao teatro do simples entretenimento.

Isso deve ser confrontado com o contexto de uma sociedade do espetáculo considerando que o universo do teatral/real não pode mais que ser um elemento integrado, que não é indiferenciado dos fluxos da sociedade. Por isso mesmo pode-se pensar que, se o consumo é espetacularizado, e as práticas de ficcionalização do cotidiano se expandiram exponencialmente, a insistência do retorno ao real propicia a politização do real. Ao mesmo tempo, é importante reconhecer que esta forma de resistência cultural encontra dificuldades na hora de se diferenciar dos procedimentos midiáticos e das ações do marketing, que tem impregnado nossas práticas de produção teatral. Como aponta Sanchez, existe o risco de que esta busca do real e a confusão de realidade e ficção sejam utilizadas apenas para sua conversão em espetacularização do privado. ${ }^{5}$ Seria preciso então compreender como o real, ou o efeito de realidade, poderia superar

5 Ainda nessa linha de pensamento, diz Sanchez, referindo-se às artes de arquivo, que a busca de elementos do real na cena, ou nas artes de um modo geral, pode "degenerar em acumulação obsessiva do insignificante, do mesmo modo que o interesse documental pode se transformar em obsessão reprodutora ou voyeurismo acrítico" (SANCHEZ, 2008, p.2) 
essas condições formais para conduzir a cena para o território da experiência. A relação direta que propicia a percepção do real no contexto da ficção permitiria "a ruptura do marco representacional e a aparição imediata do real" (SANCHEZ, 2007, p.37).

Nesse sentido, é interessante observar a proposta de Beatriz Catani (2008) que diz que sempre trata de que a representação não seja representação de algo, uma homologação, mas sim que tenha certa autonomia e seja um acontecimento do real.

O real é um elemento chave da cena moderna desde que ela estabeleceu que fazer teatro é antes de mais nada oferecer a possibilidade de um encontro entre atores e espectadores. Esse encontro deve ser sempre compreendido como um acontecimento real, cuja materialidade pode ser percebida por aqueles que situam no espaço da cena e no espaço da platéia. Pode-se considerar esse contexto como convivencial, o que é reforçado pela irrupção do real, terreno concreto do vínculo com a realidade. Esse é principal plano a partir do qual se pode pensar o funcionamento do real como elemento do teatro. Isto quer dizer que o real não vai repercutir como coisa, se não for pelo vínculo que a alusão aos elementos da realidade produz no público, considerando a dimensão do ator como sujeito real. Antes de criar novas camadas no plano da interpretação da dramaturgia, a irrupção do real reposiciona o ator (e certamente o espectador) em relação ao teatro como lugar de experimentação de vivências que se dão no contexto de uma cerimônia social diferida, como sugeriu Jean Duvignaud (1980).

A eficácia do real é um tema recorrente nessas discussões, sobretudo se considerarmos que vivemos em uma época de desconfiança daquilo que nos é oferecido como real, e estamos capacitados a supor as estratégias de ficcionalização do real (como instrumento de dominação, entretenimento ou produção de lucros). Consequentemente, é necessário refletir sobre as possibilidades de que o elemento do real produza a eficácia desejada pelos artistas que experimentam com um teatro do real. Neste sentido, é importante considerar a oportunidade de colocar em dúvida se a mera referência a um elemento da realidade produziria uma "cena do real", e se as estratégias de divulgação, apoiadas na menção ao elemento do real, não são responsáveis pela corrosão do elemento vinculante da cena, porque a deslocam para o anedótico ou exótico.

Isso se combina como as transformações de comportamento que amplificaram as práticas de ficcionalização do real. Como afirma Marc Augé, estamos em uma época onde opera a ficcionalização de tudo que produz um permanente sentimento de intranqüilidade na sociedade, e um grau de incerteza que vela nossa capacidade 
de reconhecimento da realidade (AUGÉ, 1998). Isso estimularia o comportamento da permanente desconfiança, pois pouco sabemos como mensurar o que seria o real e o ficcional. Preservar a distância entre a ficção e o real, identificando quem conta e quem ouve, é condição do livre pensar (FOILLAN DE FIGUEIREDO, 2009). Quando o sujeito não pode reconhecer o plano ficcional, vê reduzidas as suas possibilidades políticas frente às narrativas, e se torna passivo na troca simbólica. Por outro lado, a clara distância entre o real e o ficcional é condição para a operação do real como elemento de suspensão do plano ficcional e convencional da cena.

No teatro, a proposta do naturalismo produziu uma relativa confusão entre o real e o realismo. Mas, como aponta Julia Elena Sagaseta: "o realismo é construção artística da realidade, pois, o realismo que busca produzir um mundo parecido ao real, não é mais que um artifício" (SAGASETA, 2008, p.1). É interessante observar como, a partir dessa busca, produziu-se uma inversão na qual o esforço de aproximação com a realidade proposta pelo realismo/naturalismo se converteu em exemplo de artificialidade.

Já na obra de Meyerhold, podemos ver uma crítica à incapacidade do naturalismo de alcançar a verdade da experiência no acontecimento teatral. $\mathrm{O}$ diretor russo negou de forma categórica o projeto de um ator que se coloque a serviço do texto e da personagem como instrumento da construção de uma cena que representaria a realidade em todos seus detalhes. Consciente da impossibilidade da realização dessa tarefa de forma completa, Meyerhold reivindicou um "teatro da convenção", um teatro "teatral", no qual a experiência real do ator na cena e a possibilidade de uma atuação concreta do espectador fossem os vetores de um encontro. Essa perspectiva politizou o projeto cênico meyerhodiano, de tal modo que o diretor forjou a noção de um ator tribuno. Este ator se relacionaria por meio da ficção e da teatralidade com o mundo real seu e do espectador. Disse Meyerhold em sua conferência sobre aquilo que ele chamou de "Teatro da convenção":

Se o teatro volta a ser dinâmico, que seja até as últimas conseqüências. O teatro deve revelar definitivamente sua essência dinâmica; não deve ser mais, portanto, "teatro" como mero "espetáculo". Queremos reunir-nos para criar, "atuar" conjuntamente, e não só contemplar. [...] No teatro "da convenção consciente" o espectador não esquece nem por um instante que tem ante si um ator que representa, nem o ator que tem ante ele uma sala, sob seus pés um palco. (MEYERHOLD, 1992, p.174)

O diretor reforçou sua poética usando a ideia de jogo como o elemento de conexão com o real. Isso fica evidente, principalmente, em suas encenações do período chamado "Outubro Teatral". Meyerhold reivindicando a coparticipação do espectador 
afirmou que: "não queremos que o espectador observe, queremos que sua paixão seja ativa. Por isso é necessário situar ao espectador de forma que ele "penetre" muito ativamente nos ritmos do espetáculo" (MEYERHOLD, 1992, p.282). Consequentemente, o diretor pensava que o jogo do ator deveria se sustentar em uma lógica segundo a qual atuar seria estabelecer diálogos com a recepção e com seu contexto político imediato.

Então, considerando este pensamento fundamental para a criação cênica, pode-se privilegiar a hipótese do real a partir da noção de experiência do real na própria realização do espetáculo, antes de enfocar o real como referencial. Isso ainda poderia nos colocar em relação à plataforma do trabalho experimental de Jerzy Grotowski, cujo eixo pode ser relacionado com a busca de vínculos entre ator e espectador, expressão de uma experiência real compartilhada. Para reafirmar isso basta com prestar atenção às palavras do mestre polonês quando ele afirma que:

O diretor deveria saber que deve colocar em cena dois ensembles. 0 ator deveria saber que tem um contra-ensemble (ou um co-ensemble). 0 espectador deveria saber que é co-autor, que participa, que é pelo menos um figurante no espetáculo, que observa, mas é observado, que vive uma certa aventura, que participa concretamente e praticamente. Não no sentido de seu estado de alma interior (este depende também da predisposição do espectador), mas no sentido da situação do espectador. É esse o âmago da questão (GROTOWSKI, 2001, p. 71).

As possibilidades se construir hierarquias sobre os reais mais o menos reais, mais ou menos autênticos, diluem-se frente ao fato de que sempre operam diferentes percepções do real. Isto é, os atores percebem de uma forma e os espectadores de outra, o importante, como acentua Grotowski é pensar que existe vínculo entre espectadores e atores. Cabe ao diretor do espetáculo tomar consciência de como quer ou pode, dirigir esses dois grupos, para atuar sobre aquilo que é central no fenômeno teatral: o encontro dos dois. A partir dessa premissa, vale a pena refletir sobre a materialidade desse encontro, considerando que é o primeiro nível do real na cena. Antes mesmo da presença do real como tema diretamente relacionado ao material dramatúrgico, o fato de que se possa perceber e experimentar acontecimentos reais no teatro no próprio plano da realização da cena será o mais evidente para o espectador, e oferece uma dimensão única que caracteriza o evento cênico. Como arte não mediada, cujo material fundamental é o compartilhamento no espaço e no tempo da cena, o teatro sempre oferece ao espectador a possibilidade de supor a experiência real do outro (o ator) enquanto este realiza seu trabalho de geração da ficção. 


\section{Referências Bibliográficas}

AGAMBEN, Giorgio. Lo que queda de Auschwitz. El archivo y el testimonio. Homo Sacer III. Madrid: Pre-Textos, 2005.

AUGÉ, Marc. Las formas del olvido. Barcelona: Gedisa, 1998.

BAUDRILLARD, Jean. Simulacros e simulação. Lisboa: Relógio D’Água, 1991.

BARTHES, Roland. O efeito de real. In: O rumor da língua. $2^{a}$ Ed. São Paulo: Martins Fontes, 2004.

CATANI, Beatriz. Acerca de lo real. La Nación, Buenos Aires, nov., 2003.

.Catani Entrevista. Territorio Teatral. Buenos Aires, n. 3, set., 2008.

CORNAGO, Óscar. "Atuar 'de verdade'". A confissão como estratégia cênica". Urdimento, n. 13, Setembro 2009.

."Biodrama. Sobre el teatro de la vida y la vida del teatro". Latin American Theater Review. Kansas University, 39.1, Fall 2005.

DUVIGNAUD, Jean. Espectáculo y Sociedad. Cidade do México: Fondo de Cultura Económica, 1980.

FOLLAIN DE FIGUEIREDO, Vera Lúcia. Encenação da realidade: fim ou apogeu da ficção?. Matrizes, Ano 3, n. 1, ago./dez., 2009.

GROTOWSKI, Jerzy. A Possibilidade do Teatro. In: O Teatro Laboratório de Jerzy Grotowski 1959 - 1969. São Paulo, Editora Perspectiva / SESC / Fundazione Pontedera, 2001.

MARTIN, Carol. Theatre of the Real. New York: Palgrave Macmillan, 2013.

Dramaturgy of the Real on the World Stage. London: MacMillan, 2010.

MEYERHOLD. Vsevolod. Textos Teóricos. Edição Juan Antonio Hormigón. Madrid: Ediciones ADDE, 1992.

SAGASETA, Julia. Intromisiones, cruces, relaciones entre lo ficcional y lo real. Territorio Teatral, n. 3, sep., 2008.

SAISON, Maryvonne. Les théâtres du réel. Pratiques de la représentation dans le théâtre Contemporain. Paris: L'Harmattan, 1998.

SANCHEZ, José Antonio. Prácticas de lo Real en la Escena Contemporánea. Madrid: Visor Libros, 2007.

Prácticas de lo Real. Territorio Teatral, n. 3, sep., 2008. 